\title{
Evaluation of the UNREST questionnaire for testing the social resistance framework
}

\section{Citation}

Factor, Roni, Ichiro Kawachi, and David R Williams. 2013. "Evaluation of the UNREST

Questionnaire for Testing the Social Resistance Framework." Journal of Epidemiology and Community Health 67 (7): 618-24. https://doi.org/10.1136/jech-2012-201465.

\section{Permanent link}

http://nrs.harvard.edu/urn-3:HUL.InstRepos:41275602

\section{Terms of Use}

This article was downloaded from Harvard University's DASH repository, WARNING: This file should NOT have been available for downloading from Harvard University's DASH repository.

\section{Share Your Story}

The Harvard community has made this article openly available.

Please share how this access benefits you. Submit a story.

\section{Accessibility}




\title{
Evaluation of the UNREST questionnaire for testing the social resistance framework
}

\author{
Roni Factor, ${ }^{1,2}$ Ichiro Kawachi, $^{3}$ David R Williams ${ }^{3,4}$
}

${ }^{1}$ School of Criminology, University of Haifa, Haifa, Israel ${ }^{2}$ Department of Global Health and Population, Harvard School of Public Health, Boston, Massachusetts, USA ${ }^{3}$ Department of Society, Human Development and Health, Harvard School of Public Health, Boston, Massachusetts, USA

${ }^{4}$ Department of African and African-American Studies, Harvard University, Boston, Massachusetts, USA

\section{Correspondence to}

Dr Roni Factor, School of Criminology, University of Haifa, Mt. Carmel, Haifa 31905, Israel; rfactor@univ.haifa.ac.il

Received 4 May 2012 Revised 7 December 2012 Accepted 7 January 2013

Published Online First

5 February 2013
To cite: Factor $R_{\text {, }}$ Kawachi I, Williams DR. J Epidemiol Community Health 2013;67:618-624.
ABSTRACT

Background The recently developed social resistance framework addresses a widespread pattern whereby nondominant minority groups, such as ethnic/racial minorities and people of low socioeconomic status, often engage in unhealthy and risky behaviours at higher rates compared with society at large. The framework suggests that power relations within society may encourage members of non-dominant minority groups to actively engage in acts of everyday resistance, which may include risky and unhealthy behaviours.

Methods The current paper develops and psychometrically evaluates a research tool to test this innovative framework. The UNREST questionnaire measures the key concepts of the framework, along with four high-risk and unhealthy behaviours, as well as demographic and socioeconomic characteristics. A pilot survey was conducted among representative subsamples of a non-dominant group (African-Americans) and a dominant group (Caucasians).

Results Consistent with the general premises of the framework, the evaluation of the questionnaire produced six valid and reliable scales, which were significantly correlated with some criterion-related items as well as unhealthy and risky behaviours.

Conclusions The preliminary results of our pilot study suggest that the new tool may be useful for testing the framework. The results also provide support for the framework in general.

\section{INTRODUCTION}

Members of non-dominant minority groups, such as ethnic/racial minorities and individuals of low socioeconomic status, often have higher rates of involvement in unhealthy and risky behaviours compared with the majority group in their society. ${ }^{1-5}$ In turn, these behaviours have a welldocumented impact on morbidity and mortality. ${ }^{6}$

Previous studies have suggested various explanations for this phenomenon, ${ }^{7}$ including the diminishing returns hypothesis, ${ }^{8}$ stress, ${ }^{9}$ discrimination, ${ }^{10}$ communication inequalities, ${ }^{11}$ variations in healthcare accessibility $^{12}$ and genetic vulnerability. ${ }^{13}$ Recently, Factor, Kawachi and Williams ${ }^{7}$ developed a social resistance framework for understanding unhealthy and high-risk behaviours among nondominant minority groups. The new framework, which aims to add to our current knowledge of the phenomenon, and not to replace existing theories, suggests that power relations within society may encourage members of non-dominant minority groups to actively engage, consciously or unconsciously, in a variety of everyday resistance behaviours. These acts include unhealthy or risky behaviours, such as smoking, alcohol and drug use, sexual risk behaviours, overeating, and unsafe driving behaviours.

The framework proposes that this takes place through two related paths. First, because of perceived historical or current discrimination, members of non-dominant groups may feel disaffected or alienated from the larger society. To voice their disaffection, they may engage in everyday social resistance acts, ${ }^{14}{ }^{15}$ which can include unhealthy and risky behaviours. In this way, nondominants express their willingness and ability to defy the dominant group, and signal to the dominant group that their power is not unlimited. Second, members of non-dominant minority groups may develop an oppositional social identity - that is, a cultural frame of reference which is opposed to that of the dominant group. Members of the non-dominant group may then feel pressure not to embrace attitudes and behaviours that are identified with the dominant group-in other words, that are seen as 'acting white'. ${ }^{16}$

To test the validity of the social resistance framework, it is essential, as a first step, to develop an empirical tool to evaluate it. The current paper describes a newly developed questionnaire which includes several scales designed to test different aspects of the theoretical framework. Then, using a pilot study of 200 blacks, or African-Americans (non-dominant group), and 200 Caucasian (majority group), we conducted various statistical analyses to psychometrically evaluate the developed scales, and compared the results across both groups.

\section{METHODOLOGY \\ Sample}

The current pilot study is based on a national representative web-based survey of 200 Caucasians and 200 African-Americans that was conducted by YouGov (formerly Polimetrix), an established webbased survey firm in the USA. The firm maintains a survey panel comprised of 1.5 million US residents who have agreed to participate in YouGov's web surveys. Survey respondents accumulate credit points which may be redeemed for small gifts, such as movie tickets and gift cards. YouGov uses a sampling method called sample matching to randomly select cases from their survey panel that closely match a target sample (eg, the large nationally representative 2006 American Community Survey) on an array of characteristics including gender, age, race, education, party identification, ideology and political interests. YouGov then weights the matched set of survey respondents to known marginals for the general US population from the target sample. Thus, the respondents in our final weighted subsamples are representative of both 
races in the USA on a broad range of sociodemographic characteristics $^{17}$ (further details can be obtained from the authors upon request). The survey achieved a $44 \%$ response rate, ${ }^{18}$ which was calculated from the number of e-mail invitations that were sent. This rate is comparable with that found in other health surveys. ${ }^{19-21}$

The idea of matching cases emerged as a way to overcome the sample quality problems experienced by most internet surveys. It has been shown, theoretically and empirically, that for large panels, the sample matching method produces a representative sample with low levels of bias and total error (due to the inclusion in the panel dataset of a large amount of auxiliary information, which makes it possible to select a balanced sample on a large set of variables). This method yields results similar to a simple random sample, and outperforms conventional estimates based on random digit dialling phone surveys. ${ }^{22} 23$ The YouGov panel, along with the sample matching method, is widely used in public opinion research as well as health research. ${ }^{17} 2425$

\section{The UNREST questionnaire}

The questionnaire we designed to test the social resistance framework is the UNREST questionnaire (for UNhealthyRESisTance). Following DeVellis ${ }^{26}$ guidelines for scale development, we followed seven steps in developing the questionnaire. Specifically, we first (1) generated an item pool; (2) determined the format of the measurements; (3) had the items reviewed by a panel of experts; then (4) added validation items. Next (5), we then administered the initial questionnaire to a small pilot study of 25 Caucasian or African-American adults, and interviewed the respondents to confirm that the items measured our main concepts. After (6) analysing the quantitative and qualitative results of the small pilot, we (7) optimised the scale length and created the final version of the questionnaire.

The UNREST questionnaire includes six scales which are central to the social resistance framework (see box 1). Four of these scales are short versions of well known existing scales: everyday discrimination, ${ }^{27}$ perceived procedural justice, noncommitment to the law ${ }^{28} 29$ and alienation. ${ }^{30}$ The two remaining scales were developed for this study to capture the two core concepts of the framework-everyday social resistance and not acting white. In those cases, we initially generated 10 and 12 items, respectively; these were then reduced to four and five items through expert review and the results of the pilot, as described above.

For all items, responses are given on a 7-point Likert scale from $1=$ strongly disagree/never to $7=$ strongly agree/very often. Scores on each scale are calculated as a weighted average of the scale's items, ${ }^{31}$ where the appropriate weights are estimated using principal components factor analysis (see below).

The UNREST questionnaire collects the following demographic and socioeconomic data: age, gender, race, attendance at religious services $(1=$ never, $5=$ more than once a week), and highest education completed. It also collects data on total household income over the last 12 months, and the number of people living in the household; the first is divided by the second to produce a measure of income per capita. A final sociodemographic item asks respondents where they believe they stand relative to other members of their community on a scale from 1 to 10 . This question produces a measure of subjective social status. ${ }^{32}$

Four outcome variables are measured by the questionnaire. Smoking is measured as the number of days the respondent smoked over the last month, multiplied by the number of cigarettes smoked on average each day. ${ }^{33}$ Alcohol consumption is calculated as the number of days the respondent consumed any

\section{Box 1 Main scales of the UNREST questionnaire}

\section{Everyday discrimination}

In your day-to-day life, how often have any of the following things happened to you ( $1=$ never, $7=$ almost every day): You are treated with less courtesy or respect than other people

You receive poorer service than other people at restaurants or stores

People act as if they think you are not smart

People act as if they are afraid of you

You are threatened or harassed

What do you think was the main reason these experiences happened to you?

(Your ancestry or national origin, gender, race, age, height, weight, other)

\section{Perceived procedural justice (1=strongly disagree, $7=$ strongly} agree)

The court and the police treat everyone equally

The punishment in the legal system usually fits the crime People like me are treated fairly and equally by the court and the police

Court and police decisions are generally fair

Alienation ( $1=$ strongly disagree, $7=$ strongly agree)

The rich get richer and the poor get poorer

What you think doesn't count very much anymore

Most people with power try to take advantage of people like you

Non-commitment to law (1=strongly disagree, 7=strongly agree) There is no need to obey laws that seem unreasonable to me It is okay to disobey a law if I'm not causing any harm to anybody

Sometimes it is okay to ignore unimportant laws

If a law is unjust, I don't have to obey it

Not acting white (1=strongly disagree, $7=$ strongly agree) I prefer to be in the company of other people of the same race as me most of the time

In general, I try to behave like other people who are of the same race as me

I prefer to dress like people of my same race

I don't like to act like people of other races

My friends don't accept people who act like someone who belongs to a different race than theirs

Social resistance ( $1=$ strongly disagree, $7=$ strongly agree) Often I find myself objecting to the symbols of the country (eg, the flag, the national anthem)

I disagree with the values that the USA represents It is okay for people who are in a difficult situation to occasionally disobey the law

Sometimes I get so frustrated I feel like damaging public property

type of alcohol over the last month, multiplied by the number of drinks consumed each day. ${ }^{34}$ Two variables capture failure to use seat belts. Each respondent reported how frequently s/he (a) drove and (b) rode in an automobile as a passenger in the last 12 months without buckling up the seat belt, on a scale from $1=$ never to $7=$ very often $^{35}$ 
Finally, the UNREST questionnaire includes several items designed to validate the new scales. First, four items are used to measure positive emotions towards the respondent's racial group. ${ }^{36}$ Specifically, respondents are asked how often they have ever felt (a) sympathy and (b) admiration for (a) AfricanAmericans and (b) Caucasians (responses are given on a 7-point scale, $1=$ never, $7=$ very often). For members of each racial group, this variable is calculated as in-group affect subtracted by affect toward the other group. Second, one item measures whether the respondent voted in past presidential elections for which he/she was eligible $\left(1=\right.$ never voted, $5=$ voted in all). ${ }^{37}$ Last, we incorporated a weighted social participation index. ${ }^{38}$ This index is derived by measuring whether during the past 12 months the respondent did any of the following: worked with other people to deal with issues facing the community; telephoned, wrote a letter, or visited a government official to express his/her views on a public issue; attended a local community or school meeting; took part in a protest, march or demonstration on a local or national issue $(1=$ never, $5=$ frequently).

\section{RESULTS}

We initially conducted a principal components factor analysis with Varimax rotation to explore the dimensionality of the questionnaire's constructs. As shown in table 1, the analysis clearly reveals six different factors, which are stable over our two subsamples. The six factors account for $65.89 \%$ of standardised variance in the Caucasian and $69.59 \%$ in the African-American subsample. The six factors represent the six main scales of the UNREST questionnaire, in the following order: everyday discrimination (F1), perceived procedural justice (F2), alienation
(F3), non-commitment to the law (F4), not acting white (F5) and social resistance (F6).

To confirm the structure of the items that emerged in the exploratory factor analysis, we performed confirmatory factor analysis for the two new scales which are central to the social resistance framework - the social resistance and not acting white scales. The initial results indicated that one item in each scale ('I disagree with the values that the USA represents'; 'I don't like to act like people of other races') showed relatively low loadings (0.34 and 0.19 , respectively), so they were eliminated from the scales. The results of the final analysis suggest a good fit of the model to the data (see figure 1 for the analysis of the nondominant group). Not surprisingly, we found a better fit for the non-dominant subsample, as its fit indices (comparative fit index $=0.99$; root mean square error of approximation $=0.04$, all items significant at $\mathrm{p}<0.01)$ were better than for the majority group (0.95 and 0.09, respectively; all items significant at $\mathrm{p}<0.01)$.

As can be seen in table 2, the Cronbach's $\alpha$ s of the scales among the non-dominant subsample (African-Americans) are higher than the traditional cut-off of $0.7,{ }^{26}$ which suggests that the scales are reliable. Similarly, for the dominant group (Caucasians), most of the scales are higher than the cut-off, though the alienation $(\alpha=0.64)$ scale is a bit lower. (This lower $\alpha$ value should be considered in light of the fact that it is more difficult to reach high $\alpha$ values in scales with a small number of items, such as the alienation scale. ${ }^{39}$ )

Comparing the mean values of the scales across both races generally confirms the assumptions of the social resistance framework (see table 2). Members of the non-dominant group experience significantly more everyday discrimination, perceive

Table 1 Exploratory factor analysis for the main UNREST items, by race

\begin{tabular}{|c|c|c|c|c|c|c|c|c|c|c|c|c|}
\hline & \multicolumn{6}{|c|}{ Caucasian } & \multicolumn{6}{|l|}{ Black } \\
\hline & F1 & F2 & F3 & F4 & F5 & F6 & F1 & F2 & F3 & F4 & F5 & F6 \\
\hline Treated with less respect & 0.90 & 0.07 & 0.11 & -0.02 & -0.01 & 0.01 & 0.90 & -0.06 & 0.10 & 0.08 & 0.03 & 0.04 \\
\hline Received poorer service & 0.90 & 0.15 & 0.12 & 0.05 & 0.02 & -0.01 & 0.86 & -0.04 & 0.10 & 0.14 & 0.11 & -0.01 \\
\hline Think you are not smart & 0.92 & 0.12 & 0.08 & 0.08 & 0.02 & 0.01 & 0.88 & -0.02 & 0.10 & 0.06 & 0.02 & 0.03 \\
\hline Afraid of you & 0.72 & -0.04 & -0.10 & -0.06 & 0.05 & 0.18 & 0.83 & -0.03 & 0.01 & 0.09 & -0.01 & 0.13 \\
\hline Threatened or harassed & 0.66 & -0.14 & -0.05 & 0.00 & -0.05 & 0.05 & 0.78 & 0.05 & 0.12 & 0.13 & -0.02 & 0.10 \\
\hline Court/police treat everyone equally & 0.08 & 0.77 & -0.24 & -0.23 & 0.10 & -0.03 & -0.06 & 0.87 & -0.17 & 0.08 & 0.14 & 0.11 \\
\hline Punishment usually fits the crime & -0.01 & 0.73 & 0.00 & -0.16 & 0.08 & 0.03 & -0.01 & 0.83 & -0.08 & 0.05 & 0.22 & -0.13 \\
\hline People like me are treated fairly/equally & 0.07 & 0.72 & -0.17 & -0.09 & 0.05 & -0.27 & -0.07 & 0.85 & -0.15 & -0.07 & 0.01 & 0.13 \\
\hline Court/police are generally fair & 0.00 & 0.90 & -0.08 & -0.12 & 0.07 & -0.13 & 0.04 & 0.89 & -0.14 & 0.04 & 0.10 & -0.10 \\
\hline Rich get richer, poor get poorer & 0.03 & -0.14 & 0.70 & 0.03 & -0.13 & 0.07 & 0.20 & -0.17 & 0.74 & -0.18 & 0.10 & -0.02 \\
\hline What you think doesn't count & 0.03 & -0.13 & 0.72 & -0.06 & 0.15 & -0.05 & 0.12 & -0.15 & 0.83 & 0.06 & 0.01 & 0.16 \\
\hline People with power try to take advantage & 0.03 & -0.06 & 0.78 & -0.07 & 0.04 & -0.01 & 0.08 & -0.16 & 0.89 & 0.03 & 0.09 & 0.04 \\
\hline No need to obey laws that seem unreasonable & 0.01 & -0.17 & -0.08 & 0.75 & 0.12 & 0.21 & 0.10 & 0.09 & -0.05 & 0.85 & 0.05 & 0.10 \\
\hline It's okay to disobey a law that doesn't cause harm & 0.04 & -0.17 & 0.01 & 0.88 & 0.06 & 0.18 & 0.14 & 0.06 & -0.05 & 0.86 & 0.05 & 0.11 \\
\hline It's okay to ignore unimportant laws & 0.00 & -0.14 & 0.04 & 0.88 & 0.03 & 0.09 & 0.07 & -0.08 & -0.05 & 0.81 & 0.04 & 0.15 \\
\hline If a law is unjust I don't have to obey it & 0.00 & -0.09 & -0.07 & 0.85 & -0.13 & 0.02 & 0.15 & -0.02 & 0.06 & 0.76 & 0.09 & 0.15 \\
\hline Prefer the company of same race & -0.02 & 0.05 & -0.08 & 0.05 & 0.84 & -0.06 & -0.03 & 0.09 & 0.12 & 0.16 & 0.76 & 0.13 \\
\hline Try to behave like people of same race & 0.11 & 0.14 & -0.09 & -0.04 & 0.75 & -0.03 & 0.07 & 0.21 & 0.06 & 0.13 & 0.74 & 0.19 \\
\hline Prefer to dress like same race & 0.06 & 0.14 & 0.08 & 0.04 & 0.77 & -0.11 & 0.08 & 0.14 & -0.02 & 0.09 & 0.82 & 0.07 \\
\hline Don't like to act like other race & -0.06 & -0.10 & 0.02 & -0.01 & 0.76 & -0.05 & -0.07 & -0.08 & 0.02 & -0.21 & 0.51 & 0.01 \\
\hline Friends don't accept people of diff. race & -0.09 & 0.09 & 0.19 & 0.05 & 0.50 & 0.25 & 0.17 & 0.23 & 0.04 & 0.31 & 0.53 & 0.13 \\
\hline Object to symbols of country & 0.04 & -0.20 & 0.00 & 0.21 & -0.10 & 0.79 & 0.09 & 0.00 & 0.08 & 0.20 & 0.16 & 0.76 \\
\hline Disagree with US values & 0.14 & -0.05 & 0.26 & 0.05 & -0.10 & 0.48 & 0.10 & -0.15 & 0.05 & 0.07 & 0.04 & 0.75 \\
\hline People in difficult situations can break the law & -0.02 & -0.04 & -0.01 & 0.49 & 0.14 & 0.63 & 0.05 & 0.12 & 0.08 & 0.54 & 0.20 & 0.57 \\
\hline So frustrated want to damage public property & 0.09 & -0.07 & -0.19 & 0.07 & 0.01 & 0.81 & 0.05 & 0.29 & 0.03 & 0.28 & 0.28 & 0.59 \\
\hline
\end{tabular}


Figure 1 Confirmatory factor analysis for social resistance and not acting white scales among African-American subsample*. *Note: standardised coefficients; all coefficients are significant at $p<0.01$.

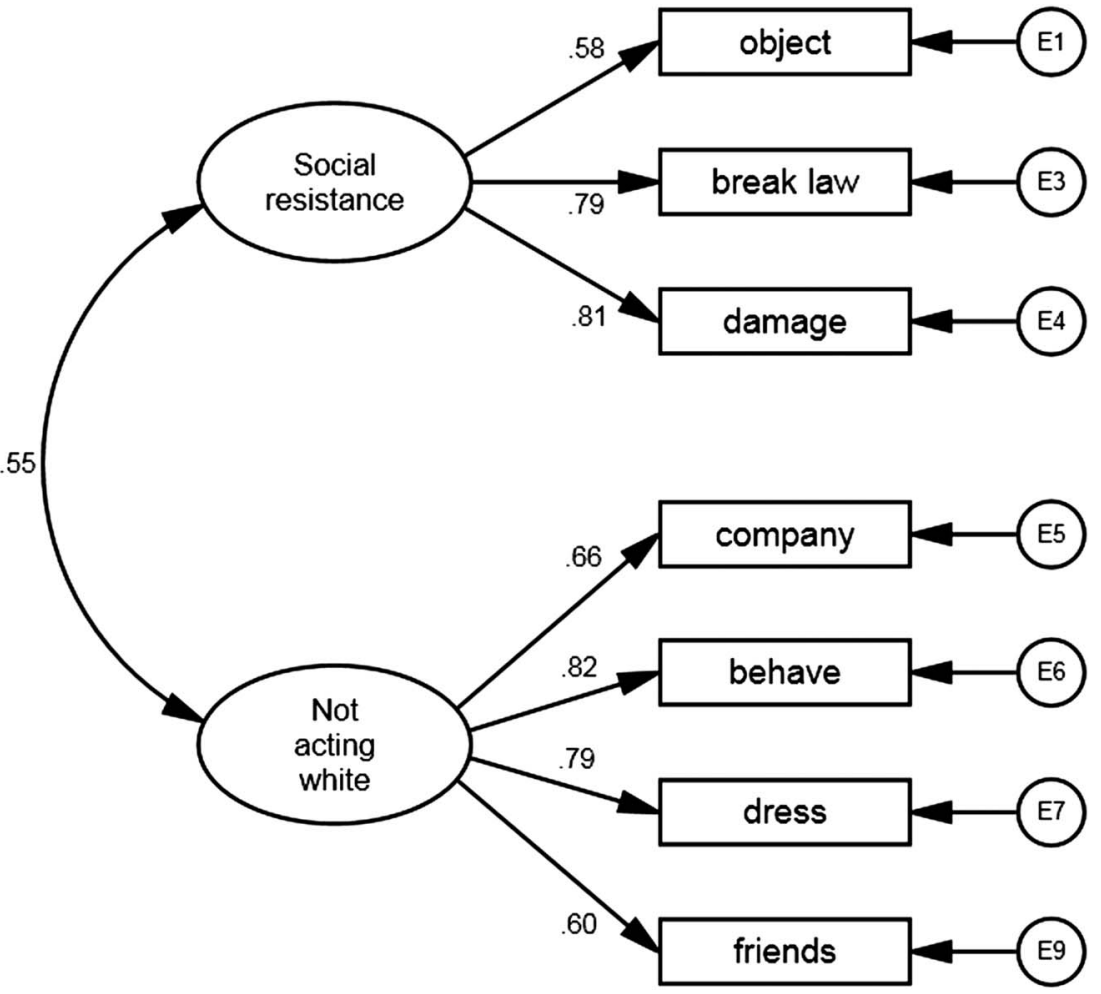

lower levels of procedural justice, are less comfortable acting white, and score higher in social resistance than their dominant-group counterparts. At a marginally significant level, they also report greater alienation. However, there is no significant difference between the races in their perceived noncommitment to the law.

Next, we tested the criterion-related validity of our new scales. We correlated the new scales with socioeconomic and demographic variables, as well as with the validation items. Table 3 shows that, in line with the premises of the social resistance framework, ${ }^{7}$ social resistance is higher among young people, people who attend religious services less often, people with lower community standing, and people who are less likely to vote in every presidential election. Among Caucasians, social resistance is also higher among people with lower income per capita, while among African-Americans, it is higher among people with higher rates of social participation. Importantly, among African-Americans, social resistance is significantly correlated with not acting white, meaning that members of the non-dominant group who score high on measures of social resistance are also less willing to be perceived as acting white. Moreover, among African-Americans, not acting white is not correlated with positive emotions towards their own racial group. This suggests that not acting white, and positive in-group emotion, are two different constructs, and our not acting white scale does not capture in-group feelings among AfricanAmericans.

Regarding unhealthy and risky behaviours consistent with the social resistance framework, individuals of both racial groups who score higher on measures of social resistance tend to consume more alcohol. African-Americans who score higher in resistance tend not to use seat belts as drivers and passengers. Similarly, African-Americans who score higher on not acting white tend not to use seat belts as drivers, while there is a positive association between the use of seat belts as a driver and not acting white among Caucasian. It is interesting to note here that

Table 2 Cronbach's $\alpha$, mean and t test of the six scales, by race

\begin{tabular}{|c|c|c|c|c|c|c|c|c|}
\hline Scale & Race & Items (n) & Cronbach's $\boldsymbol{\alpha}$ & $\mathbf{n}$ & Mean & SD & $\mathrm{t}$ & p Value \\
\hline Everyday discrimination & $\begin{array}{l}\text { Caucasian } \\
\text { African American }\end{array}$ & 5 & $\begin{array}{l}0.84 \\
0.91\end{array}$ & $\begin{array}{l}199 \\
200\end{array}$ & $\begin{array}{l}1.04 \\
2.34\end{array}$ & $\begin{array}{l}0.32 \\
1.52\end{array}$ & 11.80 & $<0.01$ \\
\hline Perceived procedural justice & $\begin{array}{l}\text { Caucasian } \\
\text { African American }\end{array}$ & 4 & $\begin{array}{l}0.84 \\
0.91\end{array}$ & $\begin{array}{l}199 \\
200\end{array}$ & $\begin{array}{l}3.88 \\
3.05\end{array}$ & $\begin{array}{l}1.39 \\
1.67\end{array}$ & 5.44 & $<0.01$ \\
\hline Alienation & $\begin{array}{l}\text { Caucasian } \\
\text { African American }\end{array}$ & 3 & $\begin{array}{l}0.64 \\
0.82\end{array}$ & $\begin{array}{l}200 \\
200\end{array}$ & $\begin{array}{l}4.82 \\
5.05\end{array}$ & $\begin{array}{l}1.38 \\
1.60\end{array}$ & 1.54 & 0.12 \\
\hline Non-commitment to law & $\begin{array}{l}\text { Caucasian } \\
\text { African American }\end{array}$ & 4 & $\begin{array}{l}0.89 \\
0.87\end{array}$ & $\begin{array}{l}199 \\
200\end{array}$ & $\begin{array}{l}2.55 \\
2.38\end{array}$ & $\begin{array}{l}1.51 \\
1.43\end{array}$ & 1.14 & 0.26 \\
\hline Not acting white & $\begin{array}{l}\text { Caucasian } \\
\text { African American }\end{array}$ & 4 & $\begin{array}{l}0.74 \\
0.80\end{array}$ & $\begin{array}{l}200 \\
200\end{array}$ & $\begin{array}{l}3.34 \\
2.71\end{array}$ & $\begin{array}{l}1.37 \\
1.45\end{array}$ & 4.47 & $<0.01$ \\
\hline Social resistance & $\begin{array}{l}\text { Caucasian } \\
\text { African American }\end{array}$ & 3 & $\begin{array}{l}0.75 \\
0.75\end{array}$ & $\begin{array}{l}200 \\
200\end{array}$ & $\begin{array}{l}1.80 \\
2.12\end{array}$ & $\begin{array}{l}1.14 \\
1.34\end{array}$ & 2.62 & 0.01 \\
\hline
\end{tabular}


Table 3 Pearson correlations of social resistance and not acting white scales with socioeconomic, demographic and validation variables and unhealthy behaviours, by race

\begin{tabular}{|c|c|c|c|c|}
\hline & \multicolumn{2}{|l|}{ Caucasian } & \multicolumn{2}{|l|}{ African-American } \\
\hline & Social resistance & Not acting white & Social resistance & Not acting white \\
\hline Not acting white & -0.02 & & $0.46^{* * *}$ & \\
\hline \multicolumn{5}{|l|}{ Socioeconomic and demographic variables } \\
\hline Age & $-0.36^{* * *}$ & 0.06 & $-0.31 * * *$ & $-0.14^{*}$ \\
\hline Attends religious services & $-0.17^{*}$ & 0.06 & $-0.22^{* *}$ & -0.12 \\
\hline Highest education completed & -0.10 & -0.02 & -0.07 & -0.04 \\
\hline Community standing & $-0.15^{*}$ & -0.02 & $-0.19^{*}$ & -0.09 \\
\hline Income per capita & $-0.18^{*}$ & -0.02 & 0.02 & 0.03 \\
\hline \multicolumn{5}{|l|}{ Validation variables } \\
\hline Voted all presidential elections & $-0.29 * * *$ & -0.05 & $-0.17^{*}$ & -0.07 \\
\hline Social participation index & 0.09 & -0.08 & $0.29^{* * *}$ & 0.10 \\
\hline Positive in-group emotions & -0.13 & $0.36^{* * *}$ & -0.03 & 0.01 \\
\hline \multicolumn{5}{|l|}{ Risky and unhealthy behaviours } \\
\hline Smoking & 0.01 & 0.05 & 0.06 & -0.02 \\
\hline Alcohol consumption & $0.15^{*}$ & 0.07 & $0.20^{* *}$ & 0.06 \\
\hline Driving without seat belt & 0.06 & $-0.14^{*}$ & $0.37^{* * *}$ & $0.19^{* *}$ \\
\hline Riding as passenger without seat belt & 0.13 & -0.11 & $0.31^{* * *}$ & 0.11 \\
\hline
\end{tabular}

a similar pattern was found when we partialed out the potential contribution of everyday discrimination, which was previously found to be related to unhealthy and risky behaviours. Among Caucasians, a significant partial correlation was found between social resistance and alcohol consumption, and a negative partial correlation between not acting white on the one hand, and non-use of seat belts as a driver and passenger on the other. Among African-Americans, social resistance showed a significant partial correlation with smoking and alcohol consumption, and a marginally significant partial correlation with non-use of seat belts as a driver and passenger.

Finally, using multivariate linear regressions with steps and an F-test, we explored whether inclusion of the new scales-social resistance and not acting white-increases the explained variance of the risky and unhealthy behaviours beyond what is explained by the socioeconomic and demographic variables and the four traditional scales (everyday discrimination, perceived procedural justice, alienation and non-commitment to law). These analyses indicate that among African-Americans, the inclusion of the social resistance scale significantly increases $(p \leq 0.03)$ the explained variance of alcohol consumption and not using seat belts as a driver and a passenger, and increases at a marginally significant level $(p=0.9)$ the explained variance of smoking. The inclusion of the not acting white scale significantly increases the explained variance only for not using seat belts as a driver among the Caucasian sample $(\mathrm{p}<0.01)$. (Results for these analyses can be obtained from the authors upon request.)

\section{DISCUSSION AND CONCLUSIONS}

The literature provides ample evidence that non-dominant minorities in numerous societies tend to engage in unhealthy and risky behaviours at higher rates than the dominant or majority group, although the pattern is not uniform. To better understand this phenomenon, Factor $\mathrm{et}_{\mathrm{al}} \mathrm{l}^{7}$ recently developed the innovative social resistance framework. Briefly, the model suggests that power relations in society may encourage members of non-dominant minorities to engage in everyday acts of social resistance that include unhealthy and risky behaviours. In the current study, we sought to develop and psychometrically evaluate a tool that will help researchers test the social resistance framework.

The current pilot study evaluates the UNREST questionnaire, which we developed to test the main concepts of the social resistance framework. We conducted a nationwide web-based survey with a representative sample of 200 Caucasian (a majority group) and 200 African-Americans (a non-dominant minority group-the main target of the framework). The preliminary results of the psychometric evaluation suggest that the questionnaire produced six different valid and reliable constructs. We found mixed results for the two new scales which are central to the framework-social resistance and not acting white. The social resistance scale is significantly correlated with criterionrelated validation variables, including age, attendance at religious services, socioeconomic status, voting and social participation. The not acting white scale, on the other hand, was not found to be correlated with most of the criterion-related validation items. This may imply that the scale was not well articulated, that we failed to find accurate validating items, or, alternatively, that avoidance of acting white is indeed a separate construct which adds a new facet beyond the commonly used variables.

The positive association which we found between social resistance and social participation among African-Americans calls for future studies to validate this finding and explore the mechanisms that might underlie this positive association. Moreover, future studies should explore the interactions between social resistance, social participation and risky behaviour, and test whether individuals who are or who perceive themselves as blocked from social participation (eg, because they think it will not be helpful, or because of physical or educational limitations) have higher levels of social resistance.

The social resistance scale was positively correlated with alcohol consumption for both subsamples, and with non-use of seatbelts as a driver and passenger in the African-American sample. The not acting white scale was found to be significantly 
and positively correlated with non-use of seat belts as a driver for the African-American subsample, and negatively correlated for the Caucasian subsample. Moreover, the multivariate regressions indicate that the social resistance scale contributes significantly to the explained variance of the unhealthy and risky behaviours-beyond the traditional constructs and sociodemographic variables-among African-Americans but not among Caucasians. These results indeed provide preliminary support for the predictions of the social resistance framework.

The finding that social resistance was related to alcohol consumption among the dominant as well as the non-dominant group may indicate that the social resistance framework-which focuses on the use of unhealthy and risky behaviours as expressions of resistance among non-dominant minorities-should be refined. It may be that the framework is actually applicable to sub-groups within both the groups studied, such that social resistance effects are influenced by intervening variables related to an individual's social position and the coping mechanisms he/ she adopts. In other words, individuals who feel alienated from the larger society, regardless of the reason, may also engage more in high-risk behaviours as a means of voicing their disaffection. This interesting finding should be confirmed in future studies with larger samples. Likewise, future studies should examine cases of individuals within each group who express the other group's expected pattern of perceptions and behaviour. Finally, an important avenue for future research is the relationship between the social resistance construct and antisocial behaviours. Such studies may provide both interesting theoretical insights and, possibly, avenues for intervention.

It is important to mention the limitations of the current study. First, the preliminary results presented above are based on two relatively small samples. Larger samples might provide more robust results and might enable examining subgroups within the two races studied. Second, the measures in the current study are based on self-reports and, thus, are potentially subject to reporting biases. Third, due to the time constraints for this survey, not all the variables and concepts of the full social resistance model (eg, anonymity, non-commitment to specific laws) were developed and evaluated. ${ }^{7}$ Future studies should develop and test these new scales. Fourth, the not acting white scale, which to the best of our knowledge is one of the first attempts to quantify this concept in a questionnaire, should be strengthened with more items, or at least tested again in different samples.

Fifth, the current study used an online survey. This method has several advantages. For instance, respondents answering questions online may feel more anonymous, and so may answer 'sensitive' questions more sincerely. Also, online surveying offers a relatively fast and inexpensive means of reaching nationwide samples. ${ }^{40}$ Moreover, the sample matching procedure appears to be a valid and reliable method that produces outcomes similar to more conventional sampling methods (eg, phone or face-to-face surveys). Yet since the online survey is a relatively new method, it is important to validate the current tool with different sampling methods, and to explore the impact, if any, that the sampling method has on respondents' answers.

In short, this pilot study represents a first step in testing the innovative social resistance framework. Future studies should continue evaluating the UNREST questionnaire in other societies and different non-dominant groups, and should use the questionnaire with different sampling methods to test the assumptions of the social resistance framework. We hope that this approach will help us to better understand why people engage in high-risk and unhealthy behaviours, and will be useful in reducing health inequalities.
What is already known on this subject?

- Non-dominant minorities often have higher rates of involvement in unhealthy and risky behaviours compared with the majority group in their society. The recently developed social resistance framework offers a new approach to understanding this pattern. This paper develops and evaluates a questionnaire designed to test the social resistance framework- the first research tool to do so.

\section{What does this study add?}

- The developed questionnaire includes six valid and reliable scales-four short versions of well known existing scales and two new scales-that are correlated with unhealthy and risky behaviours, showing that the new research tool can be used to test the social resistance framework. The study provides preliminary support for this innovative framework, which may inform initiatives for reducing inequalities in health.

Acknowledgements The study was conducted with the support of the Takemi Program in International Health at the Harvard School of Public Health.

Contributors RF led the study conceptualisation, data collection and analysis, and the writing of the article. IK and DRW guided the study conceptualisation and assisted with the writing of the article. All authors participated in interpretation of the findings, and review and editing of the article.

Funding This work was supported by the Robert Wood Johnson Foundation Health and Society Scholars Seed Grant Program, grant number 67954.

Competing interests None.

Ethics approval Harvard School of Public Health IRB.

Provenance and peer review Not commissioned; externally peer reviewed.

\section{REFERENCES}

1 Burns FM, Evans AR, Mercer $\mathrm{CH}$, et al. Sexual and HIV risk behaviour in Central and Eastern European migrants in London. Sex Transm Infect 2011;87:318-24.

2 Factor R, Yair G, Mahalel D. Who by accident? The social morphology of car accidents. Risk Anal 2010;30:1411-23.

3 Kawachi I, Daniels N, Robinson DE. Health disparities by race and class: why both matter. Health Aff 2005;24:343-52.

4 Ujcic-Voortman JK, Bos G, Baan CA, et al. Ethnic differences in total and HDL cholesterol among Turkish, Moroccan and Dutch ethnic groups living in Amsterdam, the Netherlands. BMC Public Health 2010;10:740.

5 Stirbu I, Kunst AE, Bos V, et al. Injury mortality among ethnic minority groups in the Netherlands. J Epidemiol Community Health 2006;60:249-55.

6 Danaei G, Ding EL, Mozaffarian D, et al. The preventable causes of death in the United States: comparative risk assessment of dietary, lifestyle, and metabolic risk factors. PLoS Med 2009;6:e1000058.

7 Factor R, Kawachi I, Williams DR. Understanding high risk behavior among non-dominant minorities: a social resistance framework. Soc Sci Med 2011;73:1292-301.

8 Farmer MM, Ferraro KF. Are racial disparities in health conditional on socioeconomic status? Soc Sci Med 2005;60:191-204.

9 Jackson JS, Knight KM, Rafferty JA. Race and unhealthy behaviors: chronic stress, the HPA axis, and physical and mental health disparities over the life course. Am J Public Health 2010;100:933-9.

10 Williams DR, Yan Y, Jackson JS, et al. Racial differences in physical and mental health: socio-economic status, stress and discrimination. J Health Psychol 1997;2:335-51.

11 Viswanath K. Public communications and its role in reducing and eliminating health disparities. In: Thomson GE, Mitchell F, Williams MB, eds. Examining the health disparities research plan of the national institutes of health: unfinished business. Washington, DC: Institute of Medicine, 2006:215-53. 
12 Shi L, Starfield B, Politzer R, et al. Primary care, self-rated health, and reductions in social disparities in health. Health Serv Res 2002;37:529-50.

13 Adler NE, Rehkopf DH. U.S. Disparities in health: descriptions, causes, and mechanisms. Annu Rev Public Health 2008;29:235-52.

14 Scott JC. Weapons of the weak: everyday forms of peasant resistance. New Haven: Yale University Press, 1985.

15 Scott JC. Domination and the arts of resistance: hidden transcripts. New Haven: Yale University Press, 1990.

16 Fordham S, Ogbu JU. Black students' school success: coping with the "burden of 'acting white'". Urban Rev 1986;18:176-206.

17 Gerber AS, Patashnik EM, Doherty D, et al. The public wants information, not board mandates, from comparative effectiveness research. Health Aff 2010;29:1872-1.

18 American Association for Public Opinion Research. Standard definitions: final dispositions of case codes and outcome rates for surveys. 6th edn. Deerfield, IL: AAPOR, 2009.

19 Lee $S$, Brown ER, Grant D, et al. Exploring nonresponse bias in a health survey using neighborhood characteristics. Am J Public Health 2009;99:1811-17.

20 Schneider KL, Clark MA, Rakowski W, et al. Evaluating the impact of non-response bias in the behavioral risk factor surveillance system (BRFSS). J Epidemiol Community Health 2010;66:290-5.

21 Good M, Johnson K, Price A. 2004 Oklahoma health care insurance and access survey: select results. Oklahoma City, OK: Oklahoma Health Care Authority, 2005.

22 Rivers D. Sampling for web surveys. Joint Statistical Meetings; Salt Lake City, UT, 2007.

23 Vavreck L, Rivers D. The 2006 cooperative congressional election study. J Elections Public Opin Parties 2008;18:355-66.

24 Hays RD, Bjorner JB, Revicki DA, et al. Development of physical and mental health summary scores from the patient-reported outcomes measurement information system (PROMIS) global items. Qual Life Res 2009;18:873-80.

25 Sinclair SJ, Blais MA, Gansler DA, et al. Psychometric properties of the Rosenberg self-esteem scale: overall and across demographic groups living within the United States. Eval Health Prof 2010;33:56-80.

26 DeVellis RF. Scale development: theory and applications. Thousand Oaks, Calif: Sage Publications, Inc., 2003.
27 Sternthal MJ, Slopen N, Williams DR. Racial disparities in health: how much does stress really matter? Du Bois Rev 2011;8:95-113.

28 Rattner A. Structural models of injustice and illegalism in Israel. J Quant Criminol 1998;14:379-96.

29 Rattner A, Yagil D. Taking the law into one's own hands on ideological grounds. Int J Sociol Law 2004;32:85-102.

30 Weakliem DL, Borch C. Alienation in the United States: uniform or group-specific change? Sociol Forum 2006;21:415-38

31 Factor R, Mahalel D, Yair G. Inter-group differences in road-traffic crash involvement. Accid Anal Prev 2008;40:2000-7.

32 MacArthur Network on SES and Health. Sociodemographic questionnaire. University of California, 2012. http://www.macses.ucsf.edu/research/socialenviron/ sociodemographic.php (accessed 2 February 2012)

33 Minnesota Department of Health. Minnesota adult tobacco survey. Minnesota: Minnesota Department of Health, 2011.

34 Mclellan AT, Luborsky L, Woody GE, et al. An improved diagnostic evaluation instrument for substance abuse patients: The addiction severity index. Journal of Nervous \& Mental Disease 1980;168:26-33

35 Rakauskas ME, Ward NJ, Gerberich SG, et al. Rural and urban safety cultures: Human-centered interventions toward zero deaths in rural Minnesota. St. Paul, Minnesota: Minnesota Department of Transportation 2007.

36 Williams DR, Jackson JS, Brown TN, et al. Traditional and contemporary prejudice and urban whites' support for affirmative action and government help. Soc Probl 1999;46:503-27.

37 Brady HE, Verba S, Schlozman KL. Beyond SES - a resource model of political-participation. Am Political Sci Rev 1995;89:271-94.

38 American National Election Studies. Post-election questionnaire. Ann Arbor: American National Election Studies, 2004.

39 Keizer R, Dykstra PA, Poortman AR. Life outcomes of childless men and fathers. Eur Sociol Rev 2010;26:1-15.

40 Rhodes SD, Bowie DA, Hergenrather KC. Collecting behavioural data using the World Wide Web: Considerations for researchers. J Epidemiol Community Health 2003;57:68-73

\section{Correction}

Y Xu, P Dadvand, J Barrera-Gómez et al. Differences on the effect of heat waves on mortality by sociodemographic and urban landscape characteristics. J Epidemiol Community Health 2013;67:6 519-525.

The first three columns in Table 1 were incorrect in this paper. The numbers in the '10th' column should be moved to the 'Mean' column; the numbers in the 'Mean' column should be moved to the 'Minimum' column; and the numbers in the 'Minimum' column should be moved to the '10th' column. The correct table is below.

J Epidemiol Community Health 2013;67:624. doi:10.1136/jech-2012-201899corr1

Table 1 Descriptive statistics of census tract variables for the Barcelona metropolitan area (Spanish census, 2001)

\begin{tabular}{|c|c|c|c|c|c|c|c|}
\hline \multicolumn{8}{|l|}{ Percentiles } \\
\hline Census tract variables & Mean & Minimum & $10^{\text {th }}$ & $30^{\text {th }}$ & $70^{\text {th }}$ & $90^{\text {th }}$ & Maximum \\
\hline$\%$ Residents > $>4$ yr. $^{1}$ & 21.4 & 0.9 & 12.3 & 16.7 & 23.6 & 28.6 & 51.0 \\
\hline$\%$ Low education ${ }^{2}$ & 10.3 & 0.0 & 4.0 & 6.8 & 13.5 & 20.4 & 58.0 \\
\hline$\%$ Manual workers ${ }^{3}$ & 44.4 & 10.0 & 23.2 & 36.4 & 62.0 & 72.7 & 89.6 \\
\hline$\%$ Unemployment $^{4}$ & 12.7 & 3.7 & 8.3 & 10.5 & 14.5 & 18.8 & 55.9 \\
\hline$\%$ Houses without $A C^{5}$ & 79.6 & 30.4 & 70.2 & 77.0 & 85.4 & 90.5 & 98.5 \\
\hline$\%$ Old buildings ${ }^{6}$ & 20.2 & 0.0 & 0.0 & 2.3 & 16.7 & 53.7 & 100 \\
\hline$\%$ Single dwellings ${ }^{7}$ & 17.1 & 0.0 & 0.0 & 5.6 & 20.8 & 42.4 & 98.9 \\
\hline$\%$ Perception of little surrounding greenness ${ }^{8}$ & 38.3 & 1.8 & 14.2 & 25.6 & 49.5 & 66.3 & 91.7 \\
\hline Percent tree cover ${ }^{9}$ & 3.8 & 1.1 & 2.1 & 2.7 & 3.8 & 6.3 & 49.2 \\
\hline \multicolumn{8}{|c|}{$\begin{array}{l}{ }^{1} \text { Percentage of residents aged } 65 \text { years or older } \\
{ }^{2} \text { Percentage of residents ( } 16-29 \mathrm{yr} \text {.) who are illiterate or have not completed primary school education } \\
{ }^{3} \text { Percentage of manual workers among residents } \geq 16 \mathrm{yr} \text {. } \\
{ }^{4} \text { Percentage of unemployed residents } \geq 16 \mathrm{yr} \text {. } \\
{ }^{5} \text { Percentage of houses without air conditioning } \\
{ }^{6} \text { Percentage of buildings that were built before } 1920 \\
{ }^{7} \text { Percentage of single dwellings } \\
{ }^{8} \text { Percentage of residents perceiving little surrounding greenness } \\
{ }^{9} \text { Weighted average of tree cover percentage (MODIS Vegetation Continuous Fields (2002-2003)) in a bu }\end{array}$} \\
\hline
\end{tabular}

